\title{
CoRONAVÍRUS EM MEMES: POTENCIALIDADES PEDAGÓGICAS DE LER EM CIÊNCIAS
}

\author{
CORONAVIRUS IN MEMES: PEDAGOGICAL POTENTIALITIES OF READING IN \\ SCIENCES
}

DOI: 10.23926/RPD.2526-2149.2020.v5.n2.p1191-1210.id766

\section{Paula Roberta Galvão Simplício \\ Mestra em Ensino de \\ Ciências e Matemática \\ (UFAL) \\ Professora da Faculdade \\ Raimundo Marinho (FRM) \\ paularoberta.gs@gmail.com}

\section{Lyvia Barreto Santos}

Mestranda em Ensino de

Ciências e Matemática

(UFAL)

Licenciada em Ciências

Biológicas (UFAL)

lyviabarreto44@gmail.com

\section{Adriana Cavalcanti dos Santos}

Doutorado em Educação

(UFAL)

Professora Adjunta do

Centro de Educação da

Universidade Federal de

Alagoas (UFAL).

adricavalcanty@hotmail.com

\section{Wilton Petrus dos \\ Santos}

Mestre em Educação

(UFAL)

Doutorando em Educação

(UFAL).

wiltonpetrus@yahoo.com.br
Resumo: Este artigo objetiva discutir as Tecnologias Digitais (TD) e sua utilização na sala de aula, ressaltando o papel dos memes como um potencial pedagógico para abordar temas da atualidade como o Coronavírus. Para isso, efetuou-se pesquisas em artigos científicos e análise de memes compartilhados em redes sociais. Os memes analisados dizem respeito às temáticas: morfologia do vírus, disseminação, sintomas da doença, higiene pessoal, grupo de risco e relação com outras doenças. Identificou-se que os memes possuem caráter transversal e interdisciplinar que, através do humor, abordam informações de cunho científico bem como, relacionados à linguagem gerando pensamento crítico e reflexivo. O estudo demonstrou que os memes, como gênero digital, podem ser explorados em sala de aula, pois agregam as TD aos temas que causam impacto social, político, cultural e econômico; fazendo com que as aulas de ciências tornem-se mais atrativas, capazes de desenvolver nos estudantes habilidades como "ler em ciências" tornando-os, assim, alfabetizados cientificamente. Os resultados indicam que os memes compartilhados, abordam diferentes temas e que ao analisarmos, identificamos o seu potencial pedagógico, permitindo aprofundamento e discussão sobre o novo Coronavírus.

Palavras-chave: Covid-19. Memes. Ensino de Ciências.

Abstract: This article discusses Digital Technologies (TD) and their use in the classroom, emphasizing the role of memes as a pedagogical potential to address current issues such as the Coronavirus. For this, research was carried out on scientific articles and analysis of memes shared on social networks. The memes analyzed are related to the themes: virus morphology, dissemination, disease symptoms, personal hygiene, risk group and relationship with other diseases. It was identified that memes have a transversal and interdisciplinary character that, through humor, addresses scientific information as well as, related to language, generating critical and reflective thinking. The study demonstrated that memes, as a digital genre, can be explored in the classroom, as they add DT to themes that cause social, political, cultural and economic impact; making the classes more attractive, capable of developing in students skills such as "reading in science", thus making them scientifically literate. In addition, we realized that memes appear on the network from different perspectives and that when we analyze them we understand their content and information potential, which allows a deeper understanding of the subject about the new Coronavirus. Keywords: Covid-19. Memes. Science teaching. 


\section{INTRODUÇÃO}

Diante do cenário educacional, em contexto da pandemia mundial do novo Coronavírus - vírus causador da doença Covid-19, muito tem sido discutido sobre a importância de considerar os recursos tecnológicos e abordar temas do cotidiano dos estudantes, sob a perspectiva de tornar a aprendizagem significativa (FIGUEIREDO; RODRIGUES, 2020). Desse modo, as Tecnologias Digitais (TD), têm ganhado destaque na proposição de aulas remotas e de atividades a distância.

A pandemia do novo Coronavírus trouxe preocupações para diversos países, incluindo o Brasil. Por se tratar de uma doença nova, não existem ainda planos estratégicos no que se refere ao seu controle. Nesse sentindo, a Organização Mundial da Saúde (OMS), decretou medidas preventivas, sendo a principal delas, o isolamento social, fator impactante numa sociedade em que as relações sociais se fazem tão presentes e necessárias.

No âmbito educacional, por exemplo, o isolamento social tem gerando grandes desafios, uma vez que surgiram inúmeros desdobramentos (no que se refere ao andamento do ano letivo) que tem provocado discussões, questionamentos e investigações. No entanto, observa-se que em meio a esse problema mundial, surgem aspectos positivos que são importantes levar em consideração, como a utilização responsável das TD.

As TD constituem ferramentas que podem garantir vantagens aos usuários [alunos e professores], especialmente, relacionadas ao acesso à informação e a construção de conhecimentos. Diante da referida pandemia, é crescente a necessidade de utilizar tais ferramentas como recursos pedagógicos nas instituições educacionais. A partir delas, professores e alunos, podem conectar-se a internet e terem acesso às mais variadas plataformas digitais; além de utilizarem software e aplicativos, que lhes conferem conhecimento de diversos cunhos, inclusive científico.

Diante dessas reflexões, neste artigo, delineamos questões relacionadas ao letramento digital (MATTOS, 2019) que compreendem a capacidade de coordenar recursos textuais midiáticos para articular ideias, interpretar, compartilhar e criar sentidos através de diferentes habilidades. Nessa direção, este artigo objetiva discutir as Tecnologias Digitais (TD) e sua utilização na sala de aula, ressaltando o papel dos memes como um potencial pedagógico para abordar temas da atualidade como o Coronavírus, causador da doença Covid-19, responsável pela pandemia, que em 2020, vem provocando danos à população mundial, especialmente nas áreas da saúde, economia e educação. 
O presente artigo está organizado em quatro seções. Na primeira, discutimos a respeito do ensino de ciências na perspectiva da alfabetização científica, enfatizando o lugar do indicador ler em ciências a partir das tecnologias digitais. Na segunda, retratamos sobre os vírus de modo geral, na intenção de compreender aspectos do novo Coronavírus. Na terceira, refletimos acerca dos procedimentos metodológicos, seguido de uma abordagem sobre o Coronavírus em memes e suas possíveis leituras de textos em suportes virtuais. Por fim, na quarta, procedemos a análise dos memes sobre o Coronavírus demonstrando as possibilidades de leitura para a promoção do conhecimento científico em sala de aula. Finalizamos com as considerações finais referentes ao estudo.

\section{REFERENCIAL TEÓRICO}

\subsection{ENSINO DE CIÊNCIAS E ALFABETIZAÇÃO CIENTÍFICA: O LUGAR DO INDICADOR "LER EM CIÊNCIAS"}

As aulas de Ciências podem ser mais diversificadas a partir do uso das novas metodologias de ensino que objetivam tornar os estudantes alfabetizados cientificamente (SASSERON; CARVALHO, 2011). Contudo, este é um dos principais desafios da atualidade, uma vez que, não há uma "fórmula" para que os estudantes se alfabetizem cientificamente, mas há indicadores (PIZARRO; JUNIOR, 2015) que o professor pode se atentar no planejamento das suas aulas, tornando-as mais objetivas nesse sentido.

A alfabetização científica (SASSERON; CARVALHO, 2011) constitui um processo de apropriação de conhecimento no qual os alunos podem desenvolver durante as aulas; essa apropriação perpassa pelo entendimento da informação científica e aplicação desta no cotidiano. Em outras palavras, a partir do conhecimento científico, construído nas aulas de ciências, o aluno pode ser capaz de utilizá-lo para as mais variadas atividades da sua realidade cotidiana, tornando-se sujeito autônomo e capaz de resolver problemas (SASSERON; CARVALHO, 2008).

Segundo Sasseron e Carvalho (2011), os estudantes podem ser considerados alfabetizados cientificamente a partir do desenvolvimento de alguns indicadores - os indicadores de alfabetização científica - que compreendem capacidades cognitivas a serem desenvolvidas pelos estudantes no processo de construção de conhecimento (PIZARRO; JUNIOR, 2015). Tais indicadores podem ser uma alternativa na forma como ocorreu a construção de conceitos, assim como o trabalho por investigação em sala de aula (SASSERON; CARVALHO, 2011). 
As práticas pedagógicas do professor de ciências podem ser planejadas na intenção de alcançar determinados indicadores de alfabetização científica: Ler em Ciências, Escrever em Ciências, Argumentar, Problematizar, Criar, Atuar, Investigar e Articular Ideias (PIZARRO, 2014). Sintetizando cada indicador de alfabetização científica, a autora diz que:

\begin{abstract}
Articular ideias- Surge quando o aluno consegue estabelecer relações, seja oralmente ou por escrito, entre o conhecimento teórico aprendido em sala de aula, a realidade vivida e o meio ambiente no qual está inserido; Investigar - Ocorre quando o aluno se envolve em atividades nas quais ele necessita apoiar-se no conhecimento científico adquirido na escola (ou até mesmo fora dela) para tentar responder a seus próprios questionamentos, construindo explicações coerentes e embasadas em pesquisas pessoais que leva para a sala de aula e compartilha com os demais colegas e com o professor; Argumentar - Está diretamente vinculado com a compreensão que o aluno tem e a defesa de seus argumentos apoiado, inicialmente, em suas próprias ideias, para ampliar a qualidade desses argumentos a partir dos conhecimentos adquiridos em debates em sala de aula, e valorizando a diversidade de ideias e os diferentes argumentos apresentados no grupo; Ler em Ciências - Trata-se de realizar leituras de textos, imagens e demais suportes reconhecendo-se características típicas do gênero científico e articulando-se essas leituras com conhecimentos prévios e novos, construídos em sala de aula e fora dela; Escrever em Ciências - Envolve a produção de textos pelos alunos que leva em conta não apenas as características típicas de um texto científico mas avança também no posicionamento crítico diante de variados temas em Ciências e articulando, em sua produção, os seus conhecimentos, argumentos e dados das fontes de estudo; Problematizar - Surge quando é dada ao aluno a oportunidade de questionar e buscar informações em diferentes fontes sobre os usos e impactos da Ciência em seu cotidiano, na sociedade em geral e no meio ambiente; Criar - É explicitado quando o aluno participa de atividades em que lhe é oferecida a oportunidade de apresentar novas ideias, argumentos, posturas e soluções para problemáticas que envolvem a Ciência e o fazer científico discutidos em sala de aula com colegas e professores; Atuar - Aparece quando o aluno se compreende como um agente de mudanças diante dos desafios impostos pela Ciência em relação à sociedade e ao meio ambiente, sendo um multiplicador dos debates vivenciados em sala de aula para a esfera pública (PIZARRO, 2014).
\end{abstract}

Considerando a abordagem deste artigo, delimitamos como objeto de discussão o indicador "Ler em Ciências" consistindo ser um dos mais explorados no contexto dos usos das TD, uma vez que a leitura no ambiente virtual requer uma compreensão da língua/linguagem (SPINA, 2017), seja para a compreensão de textos ou interpretação de imagens no contexto de letramento digital (SILVA, 2018). Sobre isso, Spina (2017) destaca que as tecnologias virtuais incorporadas nas mais variadas ferramentas digitais possuem um potencial pedagógico, como: desenvolvimento da leitura e escrita, capacidade de investigação de informações, e autonomia em manusear as tecnologias.

Atualmente, devido à utilização contínua da internet, aplica-se, dentre tantos recursos pedagógico, o meme para gerar e compartilhar informações de maneira rápida. $\mathrm{O}$ termo meme é usado para designar qualquer conceito da internet que é passado de pessoa para pessoa, podendo ser em formato de texto, frase, vídeo, imagens ou até mesmo palavras (CANDIDO; GOMES, 2015). Todavia, o surgimento desse termo não esteve sempre ligado ao gênero digital, 
pois foi usado pela primeira vez em analogia ao termo gene pelo biólogo Dawkins em 1976. O biólogo utilizou o termo para expressar que, semelhante ao gene, o meme faz o papel de compartilhar informação de pessoa para pessoa, ou seja, enquanto o gene carrega informações biológicas, o meme carrega ideias (LIMA-NETO; OLIVEIRA, 2019).

Tendo por base a conceituação proposta por Pizarro (2014), nos indicadores de alfabetização científica e a proposta deste artigo, o professor poderá desenvolver práticas que envolvam o "Ler em Ciências" como princípio. Nessa direção, o intuito é que os estudantes consigam desenvolver essa habilidade utilizando as tecnologias digitais, mais especificamente utilizando as redes sociais para acessar memes em formato de texto, frase e imagens de caráter científico. É importante observar, quais temáticas são relevantes para se discutir nas aulas de Ciências, apoiando-se em abordagens que tenham relação com a realidade dos sujeitos, seja em âmbito global ou local, como: meio ambiente e sustentabilidade, biodiversidade, surgimento e cura de doenças, entre outros.

Vale destacar que os memes, geralmente, apresentam um estilo humorístico para tratar de determinados assuntos, sendo que, sua criação, parte da existência de outros gêneros e das necessidades enunciativas das mais diversas culturas e finalidades previamente estabelecidas, comportando-se como ações de comunicação social e estabelecendo a cultura digital (LIMANETO; OLIVEIRA, 2019). Assim, defendemos que os memes podem desempenhar um papel fundamental na capacidade de ler o mundo, lendo em Ciências. Por esse ângulo, o "Ler em Ciência" pode proporcionar ao estudante a capacidade de conhecer e interpretar fatos reais e se questionar sobre eles, refletindo como tais fatos estão ligados a si e ao outro; podendo, desse modo, desenvolver o pensamento científico através de memes disponibilizados na internet; partindo da premissa de que os indicadores constituem habilidades que são evidências da presença de aulas que promovem a alfabetização científica (SASSERON; CARVALHO, 2011).

\subsection{VÍRUS: o CORONAVíruS}

As reflexões propostas, neste artigo, possuem como referência abordagens sobre o vírus, com especificidade voltada para o novo Coronavírus, que surgiu na China no final de 2019. Esse vírus é responsável pela pandemia de 2020 e vem causando sérios danos em diversas vertentes da sociedade; sendo então necessário, fazermos um levantamento teórico sobre esse grupo de microrganismos, na intenção de situar os leitores e propor desdobramentos para a temática. 
Em toda nossa vida, somos expostos a diferentes tipos de microrganismos, inclusive várias espécies de vírus, que podem causar distintas doenças no nosso corpo, devido à capacidade que possui de realizar alteração genética (mutação), fazendo com que o sistema imunológico não o reconheça. Essa capacidade de mutação dos microrganismos dificultam o desenvolvimento de pesquisas e o descobrimento de vacinas.

A vivência e o conhecimento de microrganismos novos que causam infecções graves, devido ao seu alto poder de patogenicidade, virulência ${ }^{1}$ e replicação, proporcionam estranheza, medo e impotência diante de um ser extremamente pequeno, como exemplo, o vírus. Este é capaz de provocar doenças que podem ser graves ao ser humano, causando efeitos devastadores.

Os vírus são organismos acelulares e se multiplicam se estiverem infectando uma célula, possuindo capacidade de reprodução e metabolismo. Quando não se apresentam dessa forma, os vírus estão inertes, não possuem atividades fora da célula do hospedeiro. Sua estrutura se caracteriza como de natureza simples, pois é constituído, basicamente, de capsídeo formado por proteína, ácido nucleico (DNA ou RNA) e em alguns casos, um envelope viral (FRANÇA; LEITE, 2018).

"Uma partícula viral completa chama-se vírion. Esse é responsável por carregar o material genético do vírus para dentro de uma célula hospedeira, onde pode ser replicado e amplificado" (FRANÇA; LEITE, 2018, p. 16); promovendo, assim, a multiplicação em larga escala dentro do organismo. A maioria dos vírus são capazes de infectar apenas tipos específicos de uma determinada espécie de hospedeiro. Raramente os vírus cruzam barreiras de espécies, mas isso pode ocorrer, como é o caso do vírus influenza ${ }^{2}$. A ligação com a célula hospedeira se dá pela interação do vírus com receptores de superfície da célula do hospedeiro por meio de ligações fracas. Ao invadir a célula hospedeira, os vírus assumem o comando da maquinaria metabólica para multiplicar-se. A multiplicação do vírus, em que um único vírion gera de algumas a milhares de novas partículas virais, podem levar a célula hospedeira à morte (FRANÇA; LEITE, 2018).

Os vírus são patogênicos, capazes de causar doenças. Podemos entender, então, que patógenos são agentes infecciosos causadoras de doenças. E a patogenicidade é a capacidade

\footnotetext{
${ }^{1} \mathrm{O}$ termo virulência pode ser usado em referência à gravidade da doença, o que significa que um patógeno é mais virulento que outro se este for capaz de causar doença mais grave (SANTOS; ROMANOS; WIGG, 2015, p. 61). ${ }^{2} \mathrm{O}$ vírus da influenza é o causador da gripe que é uma infecção aguda do sistema respiratório, com grande potencial de transmissão. O vírus da gripe (Influenza) propaga-se facilmente e é responsável por elevadas taxas de hospitalização. O vírus influenza A e B são responsáveis por epidemias sazonais, sendo o vírus influenza A responsável pelas grandes pandemias (BRASIL, 2020).
} 
de o agente infectar o hospedeiro e causar doença. Já os termos patogênese e patogenia são sinônimos e são utilizados para definir as etapas ou mecanismos envolvidos no desenvolvimento de infecção (SANTOS; ROMANOS; WIGG, 2015). Dessa forma, a patogênese viral pode ser dividida em sete etapas específicas: penetração do vírus no hospedeiro, replicação viral primária, propagação do vírus, lesão celular, resposta imunológica do hospedeiro, eliminação do vírus ou estabelecimento de uma infecção persistente e disseminação viral (FRANÇA; LEITE, 2018).

Essas etapas mostram o caminho que os vírus percorrem ao entrar no hospedeiro até o momento do estabelecimento de uma infecção e disseminação do vírus pelo organismo ocasionando uma doença. É importante entendemos que, após infecção, o indivíduo pode demorar alguns dias para apresentar os sintomas. Isto se deve ao tempo de incubação do vírus, que compreende o momento em que ele se multiplica no corpo do indivíduo, tornando-se um grande transmissor desse patógeno. Ao passo que existe a agressão ao corpo humano, o agente agressor estimula a resposta imunológica do organismo infectado, na busca de cessar a infecção, para que o organismo entre no período de convalescência, momento que indica que o corpo está se encaminhando para a recuperação gradativa.

A forma de transmissão do vírus em seres humanos pode acontecer de distintas maneiras: vertical (mãe para filho) ou horizontal (mesma espécies ou espécies distintas). Na forma vertical, é necessário que a mãe esteja contaminada e transmita a doença para o filho, por meio da placenta durante a gestação, ou no momento do contato no parto e/ou amamentação. No que se refere à transmissão horizontal, a qual é bastante comum na forma de transmissão do novo Coronavírus, pode ocorrer de diferentes modos:

- Contato: pode ocorrer diretamente de um indivíduo infectado para um hospedeiro suscetível por meio de contato sexual, saliva, contato direto com pele infectada, ou indiretamente por fômites (objetos) ou perdigotos (aerossóis de secreções respiratórias ou saliva)

-Veículo: água ou alimentos contaminados

-Vetores: os vírus podem ser transmitidos por meio de animais vertebrados ou invertebrados, sendo possível classificar os últimos em vetores biológicos (o vírus é replicado no vetor) ou mecânicos, o vetor apenas carrega o vírus (SANTOS; ROMANOS; WIGG, 2015, p. 61).

Desse modo, podemos entender a intensa disseminação do novo Coronavírus (SARSCoV-2), que são RNA vírus causadores de infecções respiratórias em uma variedade de animais, incluindo aves e mamíferos. Os Coronavírus sazonais estão em geral associados a síndromes gripais (LANA; et. al, 2020). 
O novo Coronavírus (SARS-CoV-2) é responsável por causar a doença COVID-19. O mesmo emergiu na China, onde ocasionou uma grande quantidade de infectados e mortos, destacando-se, nesse período de pandemia mundial, pela facilidade de disseminação, grau de letalidade e a falta de planejamento para contingência da doença devido as suas características desconhecidas até o presente momento. Segundo Lana,

\begin{abstract}
O novo coronavírus, denominado SARS-CoV-2, causador da doença COVID-19, foi detectado em 31 de dezembro de 2019 em Wuhan, na China. Em 9 de janeiro de 2020, a Organização Mundial da Saúde (OMS) confirmou a circulação do novo coronavírus. No dia seguinte, a primeira sequência do SARS-CoV-2 foi publicada por pesquisadores chineses. Em 16 de janeiro, foi notificada a primeira importação em território japonês. No dia 21 de janeiro, os Estados Unidos reportaram seu primeiro caso importado. Em 30 de janeiro, a OMS declarou a epidemia uma emergência internacional (PHEIC). Ao final do mês de janeiro, diversos países já haviam confirmado importações de caso, incluindo Estados Unidos, Canadá e Austrália. No Brasil, em 7 de fevereiro, havia 9 casos em investigação, mas sem registros de casos confirmados (LANA; et. al, 2020. p.1).
\end{abstract}

Nesse contexto, observamos o histórico de disseminação do Coronavírus, de modo que permite inferirmos a sua velocidade em proporcionar novos casos e em diferentes países, o que caracteriza uma pandemia ${ }^{3}$; aumentando assim, exponencialmente, o número de pessoas que contraiam a doença nos diferentes locais do mundo, incluindo o Brasil, tornando cada vez mais difícil conter a propagação do vírus.

Devido características do novo Coronavírus, essencialmente recentes, muitos estudos estão sendo realizados com o objetivo de sanar muitas dúvidas. No entanto, hoje, sabe-se que o Coronavírus pode infectar uma grande quantidade de pessoas em idades diferentes, podendo afetar mais gravemente pessoas com idade igual ou superior a 60 anos, bem como aqueles que possuem comorbidades, as quais podem ser: doença cardiovascular, diabetes mellitus, hipertensão, doença pulmonar crônica, câncer e doença renal crônica. Destacando-se, até o momento, o distanciamento social - o único modo para conter a disseminação (MCINTOSH, 2020).

Atualmente, a medida de prevenção utilizada pela maioria das regiões do Brasil é o Distanciamento Social Ampliado (DAS), quando os diferentes setores da economia e a sociedade em geral precisam permanecer em distanciamento, preferencialmente os cidadãos devem permanecer em suas residências, enquanto durar as medidas de combate à disseminação do vírus. O DAS deve ser utilizado em lugares onde o número de casos

\footnotetext{
${ }^{3}$ Segundo a OMS, uma pandemia é a disseminação mundial de uma nova doença Assim, vírus com elevadas taxas de replicação, altos índices de mutação e potencial para recombinação ou reagrupamentos podem se adaptar mais rapidamente a uma nova espécie hospedeira e tornarem-se transmissíveis entre seres humanos, emergindo como uma ameaça pandêmica (SANTOS; ROMANOS; WIGG, 2015, p. 21).
} 
confirmados tenha impactado mais que $50 \%$ da capacidade instalada do sistema de saúde local (BRASIL, 2020).

\section{METODOLOGIA}

\subsection{ASPECTOS METODOLÓGICOS DA PESQUISA}

Com o intuito de alcançar os objetivos almejados, buscamos fazer uma revisão de fontes bibliográficas (GIL, 2010) para fundamentar a pesquisa e responder os questionamentos propostos. A investigação é de cunho teórico, alicerçado em reflexões a respeito das informações científicas do novo Coronavírus e a inserção destas no contexto escolar por meio das tecnologias digitais, analisando os memes, sob a perspectiva da alfabetização científica a partir do indicador "Ler em Ciências".

Diante do cenário que a pandemia da COVID-19 causou e está causando ao mundo, é pertinente discutir elementos que potencializem e simplifiquem o processo de ensino e aprendizagem por meio dos múltiplos significados que a língua propõe por meio da multimodalidade promovendo o letramento científico ${ }^{4}$. Selecionamos alguns memes para análise, os quais tratam de abordagens no contexto do Coronavírus, como mostra o Quadro 1:

\begin{tabular}{|c|c|c|}
\hline \multicolumn{2}{|c}{ Quadro 1 - Temas abordados nos memes sobre o coronavírus } \\
\hline \multirow{4}{*}{ Vírus } & Doença & Abordagens em memes/ categorias de análise \\
\hline \multirow{4}{*}{$\begin{array}{c}\text { Coronavírus } \\
\text { (SARS-COV-2) }\end{array}$} & \multirow{3}{*}{ COVID-19 } & Morfologia do Coronavírus \\
\cline { 3 - 3 } & & Disseminação \\
\cline { 3 - 3 } & & Sintomas da doença \\
\cline { 3 - 3 } & & O isolamento social \\
\cline { 3 - 3 } & & Higiene pessoal \\
\cline { 3 - 3 } & & Grupo de risco \\
\hline
\end{tabular}

Fonte: Elaboração própria.

Analisamos os memes levando em consideração aspectos da linguagem e da informação científica abordada, para assim estabelecer meios, os quais o professor poderá trabalhar durante as aulas de Ciências, de maneira que os alunos desenvolvam a capacidade de "Ler em Ciências", articulando ideias conhecidas com novos conhecimentos. Neste caso, conhecimentos fundamentais na conjuntura da pandemia.

\footnotetext{
${ }^{4}$ Shamos (1995) considera que um cidadão letrado não apenas sabe ler o vocabulário científico, mas é capaz de conversar, discutir, ler e escrever coerentemente em um contexto não-técnico, mas de forma significativa.
} 


\subsection{Coronavírus EM Memes: das possíveis leituras de TeXTOS EM SUPORTES} VIRTUAIS

Com a utilização de tecnologias cada vez mais evidente e crescente na atualidade, é possível visualizar divisões de opiniões acerca do seu uso e finalidade. Dessa maneira, faz-se pertinente trazer o debate sobre a sua utilidade com fins pedagógicos, que preconiza a aprendizagem de diferentes sujeitos. Neste artigo, o foco de análise recai sobre o gênero digital meme, que pode ser pensado como ação do signo, isto é, como uma mediação estabelecida entre algo a que ele se refere ou se aplica, e os efeitos que são produzidos na mente de quem se põe em relação a esse objeto - informações "lidas e escritas" em sua linguagem" (HORTA, 2015, p. 21).

O uso das TD, no âmbito pedagógico, é cada vez mais evidenciada devido a aproximação dos diferentes sujeitos a essa ferramenta em seu cotidiano. Nesse ponto de vista, trazer elementos da realidade dos sujeitos é algo motivador, tanto para alunos quanto para professores. Além disso, o homem sempre sentiu a necessidade de se comunicar. Por essa razão, através da oralidade, surgiram os primeiros gêneros do discurso, como forma de inserir o homem no meio social, de fazê-lo ter vínculos comunicativos e exteriorizar seus pensamentos (LUCENA; PONTES, 2018). A comunicação através dos gêneros discursivos é essencial e uma necessidade intrínseca entre os sujeitos, e por meio deles, é possível inferir conceitos, interpretações e significados dialógicos. Dessa forma,

Todos os diversos campos da atividade humana estão ligados ao uso da linguagem. Compreende-se perfeitamente que o caráter e as formas desse uso sejam tão multiformes quanto os campos da atividade humana, o que, é claro, não contradiz a unidade nacional de uma língua. O emprego da língua efetua-se em forma de enunciados (orais e escritos) concretos e únicos, proferidos pelos integrantes desse ou daquele campo da atividade humana. Esses enunciados refletem as condições específicas e as finalidades de cada referido campo não só por seu conteúdo (temático) e pelo estilo da linguagem, ou seja, pela seleção dos recursos lexicais, fraseológicos e gramaticais da língua, mas, acima de tudo, por sua construção composicional. (BAKHTIN, 2011, p.261-262).

O entendimento e as interpretações de conceitos são demarcados pela construção de sentidos por meio das linguagens em seus diferentes contextos e formas de se expressar. Logo, os memes, são formas de comunicação e expressão por meio das linguagens que a contemporaneidade permitiu emergir diante do crescente uso das tecnologias, o que contribuiu de forma favorável para disseminação de informações importantes para a sociedade. 
No ambiente da sala de aula, cabe aos professores nortear o uso destas tecnologias para uma abordagem didática e pedagógica nas aulas de ciências proporcionando uma aprendizagem fundamentada em temáticas que perfaçam o currículo escolar e que possam proporcionar uma transversalidade e interdisciplinaridade. Dessa maneira, a inovação na escola toma novos rumos, em relação ao preponderante uso da internet.

\section{Resultados E Discussões}

\subsection{CORONAVÍRUS EM MEMES: UMA LEITURA POSSÍVEL}

Os memes selecionados para análise, nesse artigo, foram expostos com o propósito de demonstrar que o referido gênero digital pode ser utilizado em sala de aula com um potencial pedagógico, principalmente, nas aulas de ciências.

Buscamos elencar conteúdos curriculares que se dedicassem a promover uma aprendizagem de forma leve e contemporânea, o que permite a motivação e o reconhecimento por meio de alunos de diferentes faixas etárias. Esse incentivo do uso de tecnologia no âmbito escolar pode incitar a construção do conhecimento científico e a aprendizagem significativa. Selecionamos nove memes que foram compartilhados em distintas mídias, como facebook, instagram e whatsapp em diferentes períodos da pandemia. $\mathrm{O}$ meme da Figura 1 aborda a morfologia do Coronavírus, como podemos observar:

Figura 1 - Meme sobre a morfologia do coronavírus

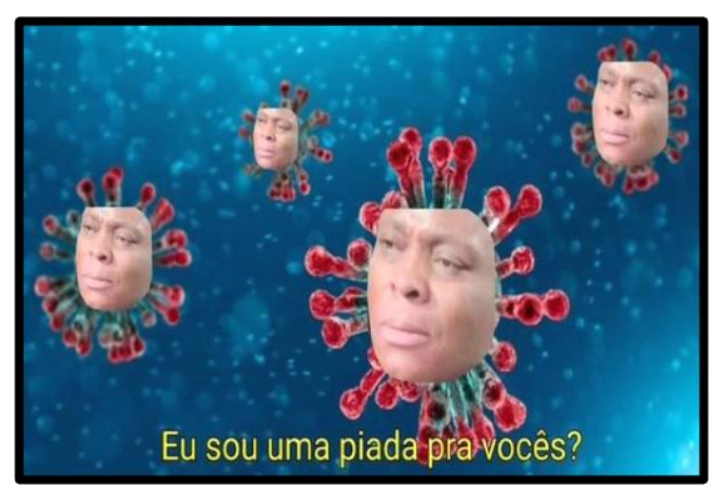

Fonte: https://rb.gy/usgo6f. Acesso em: 21 mai. 2020.

Esse e outros memes semelhantes foram bastante compartilhados nas redes sociais no início da pandemia do Coronarívus, nos quais é destacada a morfologia do Sars-Cov-2, que lembra a constituição de uma "coroa" em microscopia, fato que deu origem ao termo “Coronavírus”. De acordo com Lima (2020), o Coronavírus é um vírus zoonótico, pertencente à ordem Nidovirales, da família Coronaviridae, que causam infecções respiratórias. Os vírus dessa família foram isolados e descritos em 1937 e 1965, respectivamente, em decorrência do 
seu perfil na microscopia semelhante a coroa. Pode-se observar a linguagem verbal "Eu sou uma piada pra vocês?", que apresenta um aspecto humorístico - colocando o rosto de uma pessoa - para criticar a forma como os brasileiros estavam lidando com a doença, não dando a importância necessária as suas formas de disseminação e contaminação.

Considerando o indicativo "Ler em Ciências" (PIZARRO, 2014), o professor poderá explorar esse meme (Figura 1) para o estudo sobre as diferentes morfologias encontradas nos microrganismos, ressaltando a forma de coroa observada em microscópio do novo Coronavírus. No que se refere à disseminação do novo Coronavírus, a Figura 2 ilustra:

Figura 2 - Meme sobre a disseminação

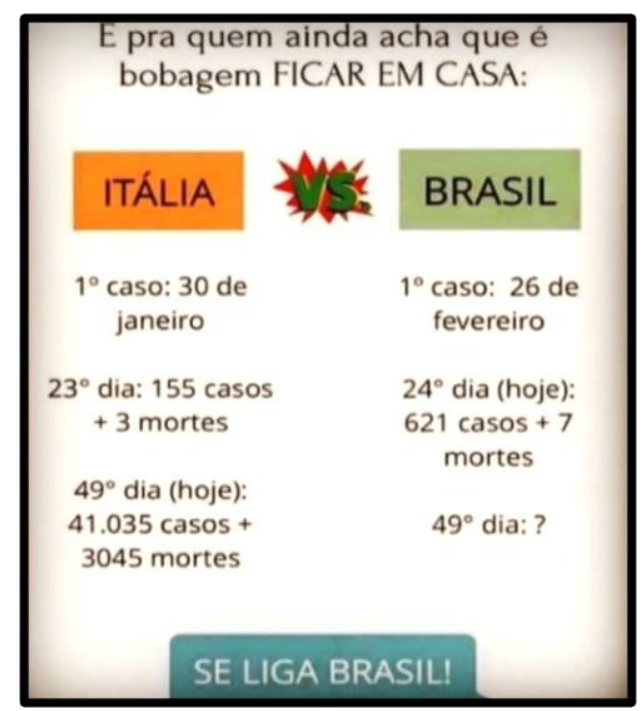

Fonte: https://rb.gy/vpiya3. Acesso em: 21 de maio de 2020.

A Figura 2 apresenta um meme que causou reflexão nas pessoas quanto a rápida disseminação do vírus associada ao descumprimento das medidas de prevenção do Coronavírus. Nele, é possível observar os altos números de casos e mortes ocorridos na Itália até determinada data, bem como os números do Brasil, e possíveis resultados que ocorreriam, caso não fossem tomadas as medidas de prevenção orientadas pela OMS.

Segundo o Boletim Epidemiológico do Ministério da Saúde brasileiro, os casos de Covid-19 tendem a aumentar entre os meses de junho, julho e agosto. Até o momento (26 de agosto de 2020), o Brasil registra 117.665 mortes, 3.717.156 casos e 2.908.848 recuperados da doença, ocupando o terceiro lugar entres todos os países do mundo (BRASIL, 2020). Nesse caso, o professor poderá trabalhar a forma como os microrganismos se disseminam, dando ênfase ao Coronavírus e relacionando o modo como outros vírus se disseminam, permitindo que os estudantes interpretem e articulem tais informações com fatos do seu cotidiano. Para o 
leitor crítico, os memes podem permitir uma reflexão sobre os sintomas da Covid-19, como ilustra a Figura 3:

Figura 3 - Meme sobre os sintomas da Covid-19

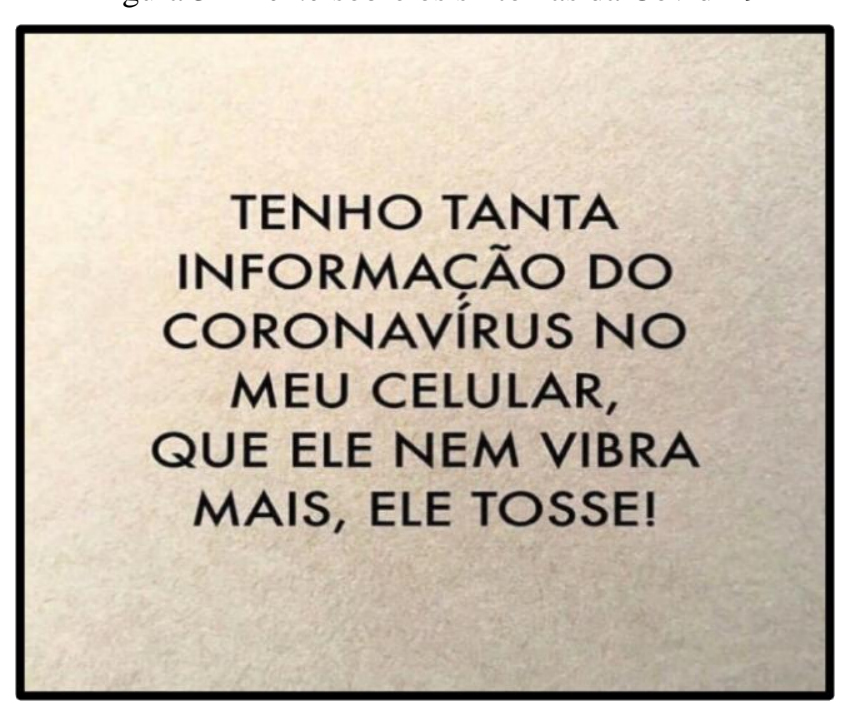

Fonte: https://rb.gy/jhs4d7. Acesso em: 21 de maio de 2020.

O meme (Figura 3) ressalta dois fatos importantes: o primeiro, refere-se a grande quantidade de informações que surgiram a respeito da Covid-19, desde quando caracterizou-se como pandemia; o segundo, trata-se dos principais sintomas observados em pessoas que foram infectadas pelo Coronavírus, sendo este semelhante ao de outras doenças causadas por outros vírus. Sobre isso, Lima expõe que:

Os principais sintomas são febre (83\%), tosse ( $82 \%)$, dispneia (31\%), mialgia (11\%), confusão mental $(9 \%)$, cefaleia $(8 \%)$, dor de garganta $(5 \%)$, rinorreia $(4 \%)$, dor torácica $(2 \%)$, diarreia $(2 \%)$ e náuseas e vômitos $(1 \%)$. Também houve registros de linfopenia em outro estudo realizado com 41 pacientes diagnosticados com COVID19 (2020, p. 5).

Com esse meme (Figura 3), o professor poderá discutir e refletir sobre os sintomas da Covid-19 e sua semelhança com os sintomas de outras doenças, fazendo com que os estudantes se atentem às informações e propaguem para outras pessoas. Dando continuidade a análise, as imagens 4 e 5 trazem como questão o isolamento social que constitui uma das recomendações do Ministério da Saúde e da Organização Mundial da Saúde (OMS) para conter a proliferação do vírus, pelo fato de não haver medicamento preventivo ou para o tratamento com eficácia cientificamente comprovada para a COVID-19. 
Figura 4 - Meme sobre o isolamento social

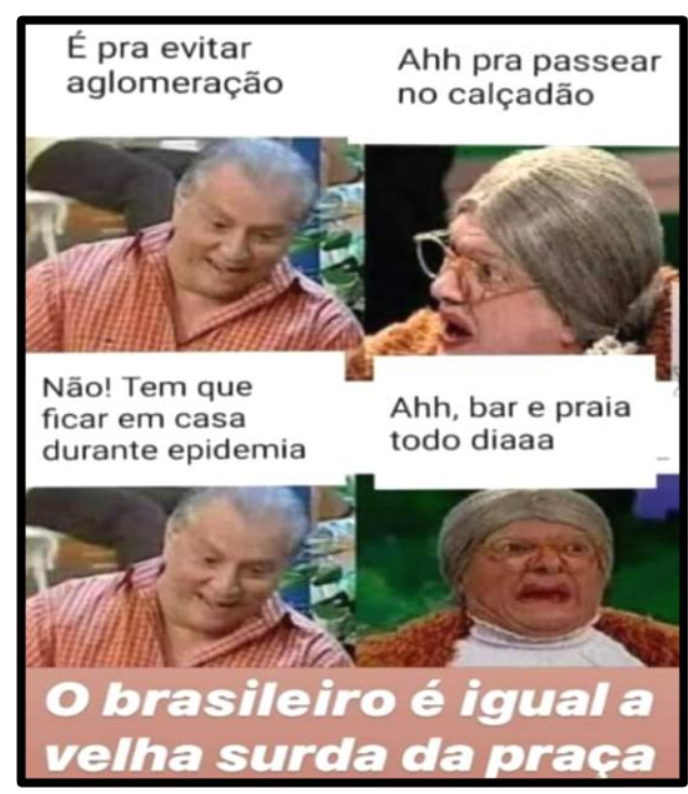

Fonte: https://rb.gy/an5fcs. Acesso em: 16 mai. 2020.

A Figura 4 retrata a falta de entendimento do povo brasileiro em cumprir as determinações do governo em relação a indicação da permanência em casa devido a situação agravante da disseminação do novo Coronavírus e a sua alta taxa de proliferação; considerando que ainda não existe uma vacina para esse vírus, trata-se de uma nova doença.

Trazendo uma personagem que faz parte de um programa de humor, a qual não possui um bom entendimento dos fatos devido a não ter uma boa audição. A Figura 4, permite a associação da personagem ao descumprimento das orientações do governo. Esse meme poderá promover, nos estudantes, a reflexão sobre como têm se comportado frente às determinações de segurança propostas pelo MS e pela OMS, de maneira que os mesmos corrijam e disseminem as informações de respeitar as recomendações, em virtude do potencial de disseminação do vírus que pode causar grandes prejuízos para a humanidade. 


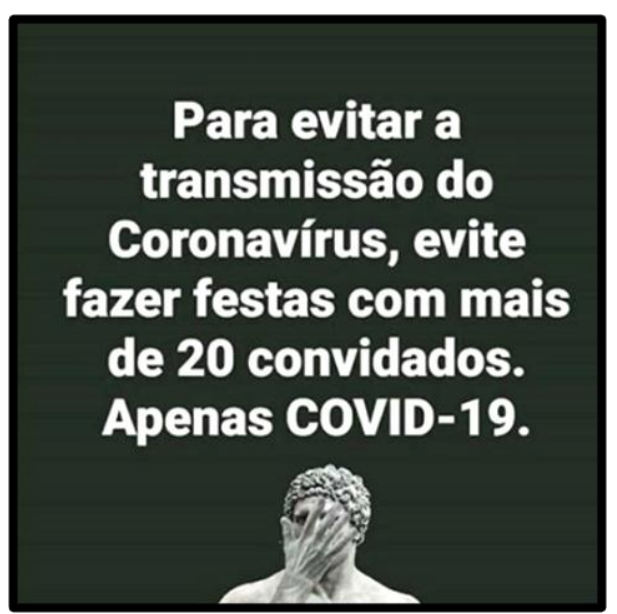

Fonte: https://rb.gy/andqkb. Acesso em 16 mai. 2020.

A Figura 5, apresenta uma crítica a população brasileira, sendo constituída de linguagem verbal e não verbal. Ela mostra a reação de grande parte dos brasileiros que não respeitam o isolamento social, sendo esse o único meio de conter a disseminação do Coronavírus. Apontase que a população não vem seguindo as recomendações que foram aplicadas em diferentes regiões do país, proporcionando um aumento do número de casos de pessoas contaminadas e mortas.

Essa situação possui relação com a falta de planejamento e conhecimento, bem como a superlotação nos sistemas de saúde, fator preocupante, mas que não está fazendo com que as pessoas se conscientizem a respeito da necessidade de continuidade no isolamento. $\mathrm{O}$ meme apresenta linguisticamente um tom irônico quando propõe a realização de uma festa, e humorístico quando apresenta condições para que o leitor relacione as palavras "convide" e "Covid", dando ênfase a doença causada pelo novo Coronavírus, COVID-19; sendo acompanhado por uma Figura que representa decepção e/ou tristeza.

O cuidado deve ser redobrado, a aprendizagem precisa continuar, então, deve-se levar para a sala de aula, temáticas que sejam atuais e proporcionem discussões por meio da exposição de saberes e contextualização da ciência. Dessa forma, urge a necessidade de promover novas possibilidades de ensino e aprendizagem por meio da contextualização com a realidade a partir dos multiletramentos (ROJO, 2012) e a sua multiplicidade de formas de linguagem podendo auxiliar na potencialização do conhecimento científico por meio de atividades motivadoras para diferentes faixas etárias. 


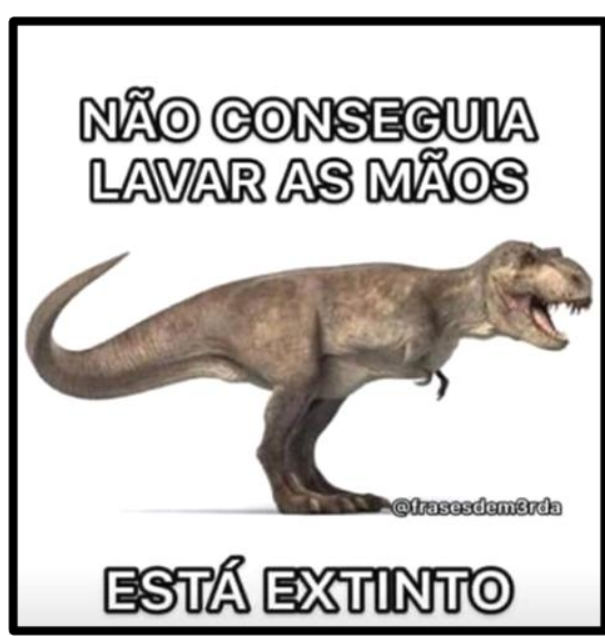

Fonte: https://rb.gy/xfxxv5 . Acesso em 16 mai. 2020.

O texto apresentado no meme (Figura 6) evidencia o fato de que a espécie de dinossauro, não tinha a possibilidade de "lavar as mãos". Assim, associa que o mesmo não sobreviveu, por não desenvolver os hábitos básicos de higiene e saúde. Implica dizer que os seres humanos necessitam desses hábitos para a sua sobrevivência, sendo reforçada essa necessidade devido à presença do novo Coronavírus. Os hábitos básicos de higiene e saúde, apesar de método simples, é eficaz, visto que os vírus são formados por proteínas em seu capsídeo, em que o sabão atua nessas proteínas desnaturando-as, afetando na patogenicidade do vírus.

A Figura 7 reflete sobre as pessoas que fazem parte dos grupos de risco para a Covid19, que compreendem pessoas idosas e com doenças que podem ser agravadas a partir do contágio com o vírus. De acordo com Lima (2020), estes indivíduos podem apresentar um estado mais grave da doença e até apresentar quadro fatal.

Figura 7 - Meme sobre grupos de risco

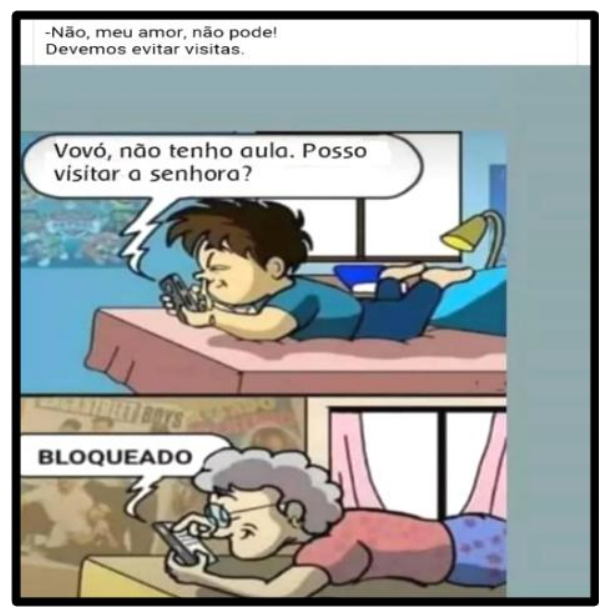

Fonte: https://rb.gy/nm0rsg. Acesso em 10 mai. 2020. 
A partir desse meme, compreende-se a importância em não visitar e não entrar em contato com pessoas idosas neste momento da pandemia. Visto que, as pessoas idosas, possuem seu sistema imunológico em declínio em função da idade. Esse sistema é responsável pela defesa do organismo contra agentes agressores.

Esse meme (Figura 7) já havia viralizado na rede em referência a outras temáticas, sendo adaptado também para a questão do Coronavírus em que uma pessoa é bloqueada em um aplicativo de mensagem quando não se quer falar ou ter contato. $\mathrm{O}$ referido meme reforça a reflexão de que os efeitos da doença podem ser bem mais graves em sujeitos idosos, podendo até ser letal em alguns casos. Segundo Lana et. al, (2020. p. 2), a letalidade do SARS-CoV-2, até o momento, "tem sido majoritariamente associada a pacientes idosos ou à presença de comorbidades que afetam o sistema imunológico". No entanto, a epidemia em alguns países ainda está em um estágio inicial de evolução e registro de casos, com relativamente poucos estudos clínicos e com muitos casos de pessoas hospitalizadas; portanto, o quadro geral da referida pandemia no mundo ainda é preliminar.

O meme (Figura 7) orienta-nos para uma explicação que auxilia na prevenção contra o novo Coronavírus, em que essa informação destaca a importância do isolamento de pessoas idosas, as quais estão inseridas no grupo de risco. Em se tratando da relação do Coronavírus com outras doenças, na Figura 8, temos:

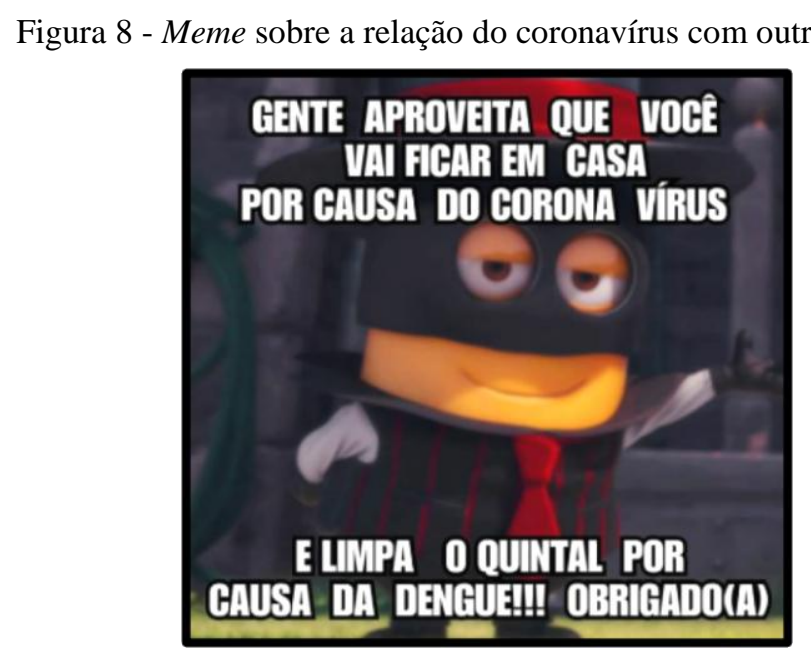

Fonte: https://rb.gy/5a8aic. Acesso em: 21 de maio de 2020.

Nesse meme, identificamos a preocupação com outra doença bastante presente na vida dos brasileiros: a Dengue. Assim, as pessoas que tiveram contato com essa postagem puderam se informar, tanto sobre a importância de se manter em casa para evitar o contágio e disseminação do Coronavírus, como sobre a realização de práticas de prevenção do mosquito 
da Dengue. Assim, os memes fazem uma interlocução de formas de expressar sentimentos e conteúdo que repercutem de forma mundial, diversas temáticas, com as quais podemos levá-las para a sala de aula e produzir conceitos e (res) significações de conteúdo.

\section{CONSIDERAÇões FinAIS}

Se por um lado as Tecnologias Digitais podem ser utilizadas de forma negativa; por outro, desempenham uma função extremamente importante: (in) formar pessoas. Neste caso, deparamo-nos com um grande aliado da escola, da aprendizagem em ciências, do ensino e do professor: os memes.

A temática do novo Coronavírus vem impactando a sociedade em diversos aspectos. Isso foi determinante para a criação e circulação de memes, nas redes sociais, com as mais diversas abordagens; sejam elas relacionadas à forma de coroa do vírus, seja pela necessidade do isolamento social para conter a disseminação da doença, bem como da higiene pessoal; seja a respeito dos grupos de risco - pessoas que podem apresentar maiores complicações.

Os memes conseguem informar e tratar de uma situação tão séria utilizando o humor e da forma mais leve possível, o que pode ser um aspecto positivo para os estudantes no momento da aprendizagem. Além disso, o gênero digital meme, pode proporcionar o desenvolvimento do indicativo "Ler em Ciências", que compreende a capacidade de interpretar textos ou imagens e saber relacionar conhecimentos novos com aqueles que já existem, contribuindo assim, para o letramento digital.

Em últimas palavras, os memes são compartilhados nas redes sociais com diferentes propósitos comunicativos e que ao analisa-los, reconhecemos o seu potencial pedagógico como meio também de disseminação do conhecimento. Nesse sentido, os memes selecionados permitem, em contextos didáticos, reflexões e aprofundamento acerca do novo Coronavírus. O uso dessa metodologia de análise do gênero meme permite contextualizar o momento que o mundo foi e está sendo afetado por uma pandemia que refletiu, sobretudo nas escolas, impossibilitando o acontecimento das aulas presenciais. Dessa forma, essa abordagem pode proporcionar significativas contribuições para a sala de aula e a tessitura de novos saberes sobre o tema.

\section{REFERÊNCIAS}

BAKHTIN, Mikhail. Os gêneros do discurso. In: Estética da criação verbal. Tradução Paulo Bezerra. 3. ed. São Paulo: Martins Fontes, 2011. p.261-306. 
BRASIL. Ministério da saúde. Gripe (influenza): causas, sintomas, tratamento, diagnóstico e prevenção. Disponível em < https://saude.gov.br/saude-de-a-z/gripe>. Acesso em 03 jun. 2020.

CANDIDO, Evelyn Coutinho Rother; GOMES, Nataniel dos Santos. Memes- uma linguagem lúdica. In: Revista Philologus, Ano 21, N 63 - Supl.: Anais da X CNLF. Rio de Janeiro: CiFEFiL, set./dez.2015. Disponível em: < http://www.filologia.org.br/rph/ANO21/63supl/_RPh63_Supl_tomo2.pdf> Acesso em: 04 Abr 2020.

FIGUEIREDO, Tiago Dziekaniak; RODRIGUES, Sheyla Costa. Professores e suas tecnologias: uma cultura docente em ação. In: Educação em Revista. Belo Horizonte. v.36, e 179031, 2020. Disponível em: <https://www.scielo.br/pdf/edur/v36/1982-6621-edur-36e179031.pdf> Acesso em: 27 mai. 2020.

FRANÇA, Fernanda Stapenhorst; LEITE, Samantha Brum. Micologia e virologia. Porto Alegre: SAGAH, 2018.

GIL, Antonio Carlos. Como elaborar projetos de pesquisa. 5. ed. São Paulo: Atlas, 2010. $184 \mathrm{p}$

HORTA, Natália Botelho. O meme como linguagem da Internet: uma perspectiva semiótica. 2015. Dissertação (Mestrado em Comunicação) - Universidade de Brasília, Brasília, 2015. Disponível em: < https://repositorio.unb.br/handle/10482/18420> Acesso em: 03 Jun. 2020.

LANA, Raquel Martins. et al. Emergência do novo coronavírus (SARS-CoV-2) e o papel de uma vigilância nacional em saúde oportuna e efetiva Cad. Saúde Pública 2020; 36(3):e00019620. Disponível em: <https://scielosp.org/article/csp/2020.v36n3/e00019620/pt/>. Acesso em: 24 Abr 2020.

LIMA, Claudio Márcio Amaral de Oliveira. O. Informações sobre o novo coronavírus (COVID-19). In: Radiol Bras. 2020 Mar/Abr;53(2):V-VI. Disponível em: https://www.scielo.br/pdf/rb/v53n2/pt_0100-3984-rb-53-02-000V.pdf. Acesso em: 21 Mai 2020.

LIMA-NETO, Vicente; OLIVEIRA, Erika Guimarães de. Memes no facebook: letramento crítico e análise de discurso crítica a partir do humor. In: Periferia, v. 11, n. 1, p. 33-53, jan./abr. 2019. Disponível em: < https://www.epublicacoes.uerj.br/index.php/periferia/article/view/36445> Acesso em: 02 Abr 2020.

LUCENA, Helyab Magdiel Alves; PONTES, Verônica Maria de Araújo. O meme no ensino de língua portuguesa do ensino médio. TICs \& EaD em Foco. São Luís, v.4, n. especial, nov. 2018. Disponível em: < https://lccp.ufra.edu.br/images/doc/Anais_Tecnologias_Digitais_na_Educa\%C3\%A7\%C3\%A 3o.pdf> Acesso em: 20 Abr 2020.

MATTOS, Elisa. Letramento(s) na contemporaneidade: desenvolvendo habilidades de leitura crítica para a inclusão digital. In: Revista de Estudos Acadêmicos de Letras. Vol. 12 N $^{\circ} 03$ - Dezembro, 2019. Disponível em: $<$ https://www.researchgate.net/publication/339070536_letramentos_na_contemporaneidade_d esenvolvendo_habilidades_de_leitura_critica_para_a_inclusao_digital > Acesso em: $20 \mathrm{Abr}$ 2020. 
MCINTOSH, Kenneth. Doença de coronavírus 2019 (COVID-19). Disponível em: <http://www2.ebserh.gov.br/documents/1688403/5111980/4.pdf/49227786-d768-470e-9ea27e021aa96cc9> Acesso em: 24 Abr 2020.

PIZARRO, Mariana Vaitiekunas. Alfabetização científica nos anos iniciais: necessidades formativas e aprendizagens profissionais da docência no contexto dos sistemas de avaliação em larga escala. 2014. 311 f. Tese (doutorado) - Universidade Estadual Paulista Julio de Mesquita Filho, Faculdade de Ciências, 2014. Disponível em: < <http://hdl.handle.net/11449/110898>. Acesso em: 21 de maio de 2020.

PIZARRO, Mariana Vaitiekunas; JUNIOR, Jair Lopes. Indicadores de alfabetização científica: uma revisão bibliográfica sobre as diferentes habilidades que podem ser promovidas no ensino de ciências nos anos iniciais. In: Investigações em Ensino de Ciências - V20(1), pp. 208-238, 2015. Disponível em:

<https://www.if.ufrgs.br/cref/ojs/index.php/ienci/article/view/66> Acesso em: 10 Abr 2020.

ROJO, Roxane. Pedagogia dos multiletramentos. In: ROJO, Roxane, MOURA, Eduardo. (Org). Multiletramentos na escola. São Paulo: Parábola, 2012.

SANTOS, Norma Suely de Oliveira; ROMANOS, Maria Teresa Villela Romanos, WIGG, Marcia Dutra. Virologia Humana, $\mathbf{3}^{\mathbf{a}}$ edição. 3. ed. - Rio de Janeiro: Guanabara Koogan, 2015.

SASSERON, Lúcia Helena; CARVALHO, Ana Maria Pessoa de. Almejando a Alfabetização Científica no Ensino Fundamental: A Proposição e a Procura de Indicadores do Processo. In: Investigações em Ensino de Ciências, Porto Alegre, v. 13, p. 333-352, dez. 2008. Disponível em: $<$ https://www.if.ufrgs.br/cref/ojs/index.php/ienci/article/view/445> Acesso em: 26 Abr 2020 .

SASSERON, Lúcia Helena; CARVALHO, Ana Maria Pessoa de. Construindo argumentação em sala de aula: a presença do ciclo argumentativo, os indicadores de Alfabetização Científica e o padrão de Toulmin. In: Ciência e Educação, Bauru, v. 17, n. 1, p. 97 - 114, jan. 2011. Disponível em: < https://www.scielo.br/pdf/ciedu/v17n1/07.pdf> Acesso em: 10 Mai 2020.

SHAMOS, Morris Herbert. The myth of scientific literacy. New Brunswick: Rutgers University Press, 1995.

SILVA, Dilcinho Luis da. Letramento digital e a aquisição de aprendizagens significativas na educação básica. In: CIET:EnPED, [S.1.], maio, 2018. Disponível em:

<https://cietenped.ufscar.br/submissao/index.php/2018/article/view/472> Acesso: em 16 Jun 2020.

SPINA, Fabio Augusto. Linguagem científica e aprendizagem significativa em abordagem de astronomia no ensino fundamental. 2017. 110 f. Dissertação (Mestrado em Formação Científica, Educacional e Tecnológica) - Universidade Tecnológica Federal do Paraná, Curitiba, 2017. Disponível em: < http://repositorio.utfpr.edu.br/jspui/handle/1/2802> Acesso em: 12 Mai 2020.

Recebido em: 19 de junho de 2020.

Aprovado em: 27 de agosto de 2020. 